\title{
Las jóvenes madres solteras universitarias: Apoyo en el cuidado de los(as) hijos(as)
}

\section{The university young single mothers: support in the care of children \\ Jovens mães universitárias solteiras: apoio no cuidado de crianças}

\author{
Rosa María Huerta Mata ${ }^{1}$ \\ 1 Profesora Investigadora, Universidad Autónoma del Estado de Hidalgo. Escuela \\ Superior de Actopan. México. Correo electrónico: huertamx@hotmail.com \\ Cómo citar este artículo en edición digital: Huerta Mata, R. M. (2019). Las jóvenes madres solteras \\ universitarias: Apoyo en el cuidado de los(as) hijos(as). Cultura de los Cuidados (Edición digital), 23 \\ (54). Recuperado de http://dx.doi.org/10.14198/cuid.2019.54.19 \\ Correspondencia: Ejército Nacional 187. Col. Las Águilas. San Luis Potosí, S. L. P. México \\ Correo electrónico de contacto: huertamx@hotmail.com \\ Recibido: 11/12/2018; Aceptado: 22/03/2019
}

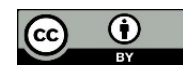

\section{ABSTRACT}

The objective of this study is to analyze the characteristics of the support networks for the care of children of single mothers who are university students in a career of sciences and thechnology.

The study was conducted from February to May in the year 2014, at the Faculty of Sciences Chemical of the Universidad Autónoma de San Luis Potosí, Mexico. We carry out the stories of life from 8 undergraduate students.

The lack or a solid and predictable support network for the care of children becomes the central element wich determines the impossibility of young women to continue their university studies.

Some young women living situations of violence within their support network and it leads them to experience a not legitimate motherhood.

Keywords: Care, young, network support, gender, higher education.

\section{RESUMO}

O objetivo deste estudo é analisar as características das redes de apoio ao cuidado de filhos de mães solteiras, estudantes universitários, em uma carreira de ciências e tecnologia.

O estudo foi realizado de fevereiro a maio no ano de 2014, na Faculdade de Ciências Químicas da Universidade Autônoma de San Luis Potosí, no México. Realizamos as histórias da vida de 8 estudantes de graduação.

A falta ou uma rede de apoio sólida e previsível para o cuidado das crianças tornase o elemento central que determina a impossibilidade de as mulheres jovens continuarem seus estudos universitários.

Algumas mulheres jovens que vivem situações de violência dentro de sua rede de apoio e apresentam uma maternidade não legítima.

Palavras chave: Cuidado, jovens, rede de suporte, gênero, ensino superior. 


\section{RESUMEN}

El objetivo de este trabajo es analizar las características de las redes de apoyo para el cuidado de los(as) hijos(as) de las madres solteras que son estudiantes universitarias en una carrera de ciencias exactas y tecnologías. El estudio fue realizado de febrero a mayo del año 2014, en la Facultad de Ciencias Químicas de la Universidad Autónoma de San Luis Potosí, México. Llevamos a cabo los relatos de vida de 8 estudiantes de nivel licenciatura.

La falta de una red de apoyo sólida y predecible para el cuidado de los(as) hijos(as) se convierte en el elemento central que determina la imposibilidad de las jóvenes para continuar con sus estudios universitarios. Algunas jóvenes viven situaciones de violencia dentro de su red de apoyo, lo que deslegitima socialmente su maternidad.

Palabras clave: Cuidado, jóvenes, red de apoyo, género, educación superior.

\section{INTRODUCCIÓN}

En la región de América Latina la figura de cuidado adjudicada a las mujeres está fuertemente asociada con la función materna, por lo tanto, el que ellas se identifiquen con las labores de cuidado las representa como "buenas madres", pues el cuidar se reconoce socialmente como una virtud propia de las mujeres. Sin embargo, en la primera década del siglo XXI en América Latina, como resultado de las políticas neoliberales, se presenta en mayor número el ingreso de las mujeres al mundo laboral, esto junto con las frecuentes crisis económicas genera dificultades para cubrir las necesidades de cuidado, debido a que las mujeres ya no se encuentran en el orden establecido de respuesta a estas demandas, a ello se le denomina "crisis de los cuidados" (Flores y Tena, 2014). La crisis de los cuidados es definida por:

“... un aumento en el número y complejidad de las necesidades de cuidados y la reducción simultánea de actores potencialmente proveedores, lo que significa una agudización de las dificultades de amplios sectores de la población para cuidarse, cuidar o ser cuidados" (Ezquerra, 2011, p. 176).

Esteban y Otxoa (2010) plantean que en la actualidad se asumen que el cuidado es tarea propia de las mujeres, así se legitima su subordinación y ellas presentan una sobrecarga de labores en el ámbito privado y público, incluso se les reconoce socialmente como cuidadoras, lo que limita el que se exijan otras formas de cuidar que sobrepasen la circunscripción de estas tareas a la familia, donde se asocia el cuidado con la jerarquía de las relaciones afectivas, por lo que, es fundamental el reconocimiento legal de otros lazos de solidaridad.

Por otro lado, Batthyány (2000) identifica en las mujeres que trabajan, que tanto las redes de cuidado familiares como las redes de cuidado informales que las asisten, están constituidas por mujeres, especialmente de la familia materna, en específico la abuela materna, así mismo, se involucra la abuela o suegra paterna, aunque esta última participa en menor medida; por su parte, los hombres se involucran, pero no de manera representativa. Por lo tanto, la dimensión relacional de los cuidados evidencia que, en la familia, específicamente en las mujeres, se concentran las labores de apoyo en el cuidado. Por lo tanto, la familiarización del cuidado consiste en encomendar en familia extensa o en la familia nuclear, en madres y hermanas, el cuidado de otros miembros (Flores y Tena, 2014; Gómez y Agudelo, 2017). En consecuencia, las redes de apoyo 
para el cuidado de los(as) hijos(as) son "marcadamente feminizadas" (Hernández, 2016). Así es como el cuidado es "el nudo crítico de la desigualdad de género", debido a que las mujeres son quienes principalmente se dedican a dichas labores, lo que limita su participación en diversos espacios públicos, de esta forma, se configuran otras desigualdades para ellas (Batthyany, 2017).

Por su parte Mari Luz Esteban (2017) sostiene que en la actualidad el debate sobre los cuidados no solamente debe centrarse en las desigualdades económicas y sociales que conlleva para las mujeres en comparación con los hombres, es necesario que se dirija la atención a lo que implica en las relaciones familiares. En este sentido, puede afectar en diversas formas a las redes familiares, lo que puede analizarse a través de dimensiones del cuidado. Algunas de las dimensiones del cuidado son: la material, que incluye el tiempo y el dinero que asumen las labores de cuidado; la dimensión emocional, donde intervienen los afectos, envuelve a las tensiones emocionales originadas por el tiempo que se dedica a los(as) hijos(as) y al trabajo y desgaste emocional ocasionado por la sobrecarga de trabajo en las mujeres (Martín Palomo, 2008).

Sales (2015) propone que dado que los cuidados son fundamentales para la autonomía, deben colocarse en el centro de la agenda política, pues el cuidado es una relación de poder donde quien provee lo hace sin crítica a la demanda de cuidado. No obstante, el cuidado es un elemento de crítica deconstructiva y constructiva, primero porque es imperativo visibilizar la subordinación que generan las formas tradicionales de cuidados, y en segundo, para poder a partir de ello, configurar nuevas vías democráticas de cuidar, donde la corresponsabilidad sea simétrica, y no solamente se implique a la familia y al Estado, sino también la solidaridad comunitaria (Sales, 2016).

Así pues, en la actualidad el cuidado se configura como un problema público, uno de los argumentos que permite visibilizarlo de este modo es la importancia de concebir que las personas somos autosuficientes $y$ dependientes a la vez, requerimos unos de otros, pensar que el ciudadano es totalmente autónomo es una ficción, por lo tanto, al ser las mujeres en quienes recaen estas labores, es necesario que el cuidado sea parte de sus derechos como ciudadanas y como elemento a tratar para alcanzar la democracia (Aguirre, 2005).

Además, una relación de cuidado involucra el que una persona llegue a imponerse sobre la otra y acapare las decisiones, lo que puede ser destructor y requiere la protección de la integridad de quienes componen la relación de cuidado (Collin, 1992). Por lo tanto, es fundamental configurar un cuidado democrático, donde prevalezca entre el dependiente y el cuidador la negociación sobre las condiciones de cuidar, sin embargo, dicha democracia no depende solamente de marcos de interacción, también es necesario que esté acompañada de elementos materiales y recursos para que las tareas de cuidado sean en circunstancias de igualdad y valoradas socialmente, de lo contrario se provoca una injusticia en el cuidado (Sales, 2014).

Como hemos constatado, la teoría sobre los cuidados se centra en las mujeres que laboran, el presente artículo se dirige al estudio de las mujeres jóvenes que se encuentran estudiando una carrera en el área del conocimiento de ciencias exactas y tecnología, y que son madres solteras. Para ello pretendemos contestar las siguientes preguntas: 
¿Cuáles son y cómo se caracterizan las redes de apoyo para el cuidado de los(as) hijos(as) de las madres solteras universitarias?

¿De qué manera las redes de apoyo para el cuidado de sus hijos(as) determinan el ingreso y permanencia de las jóvenes a la universidad?

¿Cómo influye la red familiar en el ejercicio y legitimación de la maternidad de las madres solteras universitarias?

Una de las prioridades en los objetivos del desarrollo sostenible, especificada en el objetivo cinco, es la de alcanzar en el año 2030 la igualdad de género: se pretende que para que las mujeres no vivan discriminación y logren el ejercicio de sus derechos humanos, exista la igualdad en el trabajo de cuidado de otras personas (Programa de las Naciones Unidas para el Desarrollo, 2018). Por consiguiente, visibilizar las dificultades que presentan sobre el cuidado de los(as) hijo(as) de las madres solteras universitarias en carreras de ciencias exactas y tecnología, aporta conocimiento sobre el ejercicio de los derechos de las mujeres.

\section{MÉTODO}

El presente estudio fue llevado a cabo de febrero a mayo del año 2014, en la Facultad de Ciencias Químicas de la Universidad Autónoma de San Luis Potosí, México. Esta universidad es pública y la más importante en el estado de San Luis Potosí. Cabe aclarar que la universidad no cuenta con un sistema de guardería para el cuidado de los(as) hijos(as) de los(as) estudiantes.

Para seleccionar a la población de estudio en primera instancia desarrollamos un análisis de los porcentajes en los que estaban distribuidos los estudiantes en todas las carreras de la universidad. Se identificó que en la Facultad de Ciencias Químicas, una cantidad representativa de la población estaba conformada por mujeres, quienes eran el $56 \%$ de la matrícula total de licenciatura registrada hasta diciembre de 2011 (UASLP. Universidad Autónoma de San Luis Potosí, 2012). Cabe destacar que en esta Facultad se encuentran carreras del área del conocimiento de ciencias exactas y tecnología, las cuales se caracterizan por un menor número de mujeres en comparación con el de hombres.

Otras características por las que decidimos trabajar con la población de esta Facultad, es que se define por exigir un tiempo completo de los estudiantes, en cual distribuyen en asistir a prácticas en los laboratorios y a clases teóricas. Así mismo, la Facultad de Ciencias Químicas alberga carreras que son costosas económicamente, pues los reactivos químicos los adquieren los estudiantes con sus recursos económicos y su precio es en dólares y/o euros.

Aplicamos entrevistas semi-estructuradas en profundidad a través de la metodología de relatos de vida, la cual consiste en obtener datos biográficos de determinadas temáticas de la vida de las personas. Llevamos a cabo los relatos de vida de 8 estudiantes de nivel licenciatura de la Facultad de Ciencias Químicas en la Universidad Autónoma de San Luis Potosí (UASLP). Con fines de confidencialidad modificamos los nombres de las jóvenes. Así mismo, las participantes firmaron un consentimiento informado para autorizar el uso exclusivamente académico de los datos brindados en las entrevistas.

Se utilizó la estrategia de bola de nieve para conformar la muestra. Los criterios de selección de la muestra poblacional son: mujeres jóvenes de 18 a 29 años de edad, inscritas como alumnas regulares $\mathrm{O}$ irregulares en una de las carreras de la 
Facultad de Ciencias Químicas, que sean madres sin estar casadas legalmente y que mantengan ese estado civil al momento de las entrevistas. Con dependencia económica total y/o parcial de una red de apoyo familiar y/o social. Que cohabiten con su(s) hijo(s) y/o hija(s). (Ver tabla 1).

Establecimos el criterio de inexistencia de un contrato matrimonial, para incluir distintos acuerdos de pareja, y de esta forma ampliar la diversificación de la población: jóvenes que han vivido o viven en unión libre con el padre de su(s) hijo(s) o con otra pareja, jóvenes que nunca han cohabitado con el padre de su(s) hijo(s) y que viven de manera independiente de su familia de origen, o mujeres que permanecen viviendo con su familia de origen.

Todas las entrevistas fueron grabadas, transcritas y codificadas. La metodología que se utilizó fue el análisis del contenido de los relatos de vida de las participantes, para ello, utilizamos el programa ATLAS. ti., versión 7.1.8.

TABLA 1: Características generales de las participantes

\begin{tabular}{|c|c|c|c|c|c|c|}
\hline PARTICIPANTE & EDAD & CARRERA & SEMESTRE & $\begin{array}{c}\text { N. }{ }^{\circ} \\
\text { Hijos(As) }\end{array}$ & $\begin{array}{c}\text { SEXO } \\
\text { HIJO(A) }\end{array}$ & $\begin{array}{c}\text { EDAD } \\
\text { HIJO(A) }\end{array}$ \\
\hline Laura & 20 años & $\begin{array}{l}\text { Ingeniería en } \\
\text { Bioprocesos }\end{array}$ & $6 .^{\mathrm{o}}$ & 1 & Hombre & 3 años \\
\hline Karla & 20 años & $\begin{array}{l}\text { Licenciatura en } \\
\text { Química }\end{array}$ & 1. ${ }^{\mathrm{o}}$ & 1 & Hombre & 2 años \\
\hline Alma & 24 años & $\begin{array}{l}\text { Ingeniería } \\
\text { Química }\end{array}$ & $8 .^{\circ}$ & 1 & Hombre & 5 años \\
\hline Marcela & 24 años & $\begin{array}{l}\text { Ingeniería en } \\
\text { Alimentos }\end{array}$ & $6 .^{\circ}$ & 1 & Hombre & 4 meses \\
\hline Leticia & 24 años & $\begin{array}{l}\text { Licenciatura en } \\
\text { Químicofarmaco } \\
\text { biólogo }\end{array}$ & 7. $\stackrel{9}{9}$ & 1 & Mujer & 3 años \\
\hline Fernanda & 22 años & $\begin{array}{l}\text { Ingeniería en } \\
\text { Alimentos }\end{array}$ & $6 .^{\stackrel{9}{ }}$ & 1 & Hombre & 1 año, 9 meses \\
\hline Fátima & 25 años & $\begin{array}{l}\text { Licenciatura en } \\
\text { Químicofarmaco } \\
\text { biólogo }\end{array}$ & $1 .^{\mathrm{o}}$ & 1 & Hombre & 2 años, 6 meses \\
\hline Sofía & 21 años & $\begin{array}{l}\text { Ingeniería } \\
\text { Química }\end{array}$ & $6 .^{\mathrm{o}}$ & 1 & Mujer & 2 años, 10 meses \\
\hline
\end{tabular}

\section{Desarrollo}

Existen dos elementos que en la vida diaria llegan a limitar la presencia de las jóvenes en sus hogares para el cuidado de sus hijos(as): uno es el horario escolar que les exige al día una presencia por largo tiempo en la universidad (sobre todo en semestres avanzados, o si no logran obtener un horario corrido). Por otro lado, la mayoría de estas jóvenes habitan en lugares distantes de la universidad, lo que les obliga a invertir en promedio, una hora de camino en el trasporte urbano, adicionalmente, les significa una inversión de tiempo y dinero si realizan varios viajes al día, en las horas en las que no tienen clases, de modo que, muchas optan por no ir a sus casas hasta terminar su jornada escolar. 
En el análisis sobre las trayectorias de las redes de apoyo que han tenido para el cuidado de sus hijos(as) a partir de que las jóvenes son universitarias. (Ver figura 1), identificamos diversidad sobre el cuidado, el cual lo pueden llevar a cabo: parientes, vecinas, hermanas de compañeras, amigas, compañeros, personal docente, las madres, las suegras, el padre de sus hijos(as), las hermanas, la madre del padre de su hijo(a) (aunque no sean pareja). En el primer año de edad, los niños y las niñas son cuidados por familiares, especialmente las madres, hermanas, suegras (algunas poseen las posibilidades económicas para pagar una guardería privada). En algunas guarderías particulares les ofrecen una beca como madres solteras, pero admiten a los niños y niñas hasta el primer año de edad, así mismo, debido al problema de escasez de las becas, es difícil que todas logren dicho beneficio. Martín Palomo (2008) señala que el limitando servicio público para el apoyo en el cuidado de los(as) hijos(as), está siendo subsanado por las mujeres, especialmente en el apoyo intergeneracional. Los resultados en las trayectorias de la red de apoyo para el cuidado de los(as) hijos(as) de las participantes, en general reproduce el patrón de feminización intergeneracional del cuidado.

\section{FIGURA 1: Trayectorias de las redes para el cuidado de los(as) hijos(as)}

\section{a partir de que son universitarias}

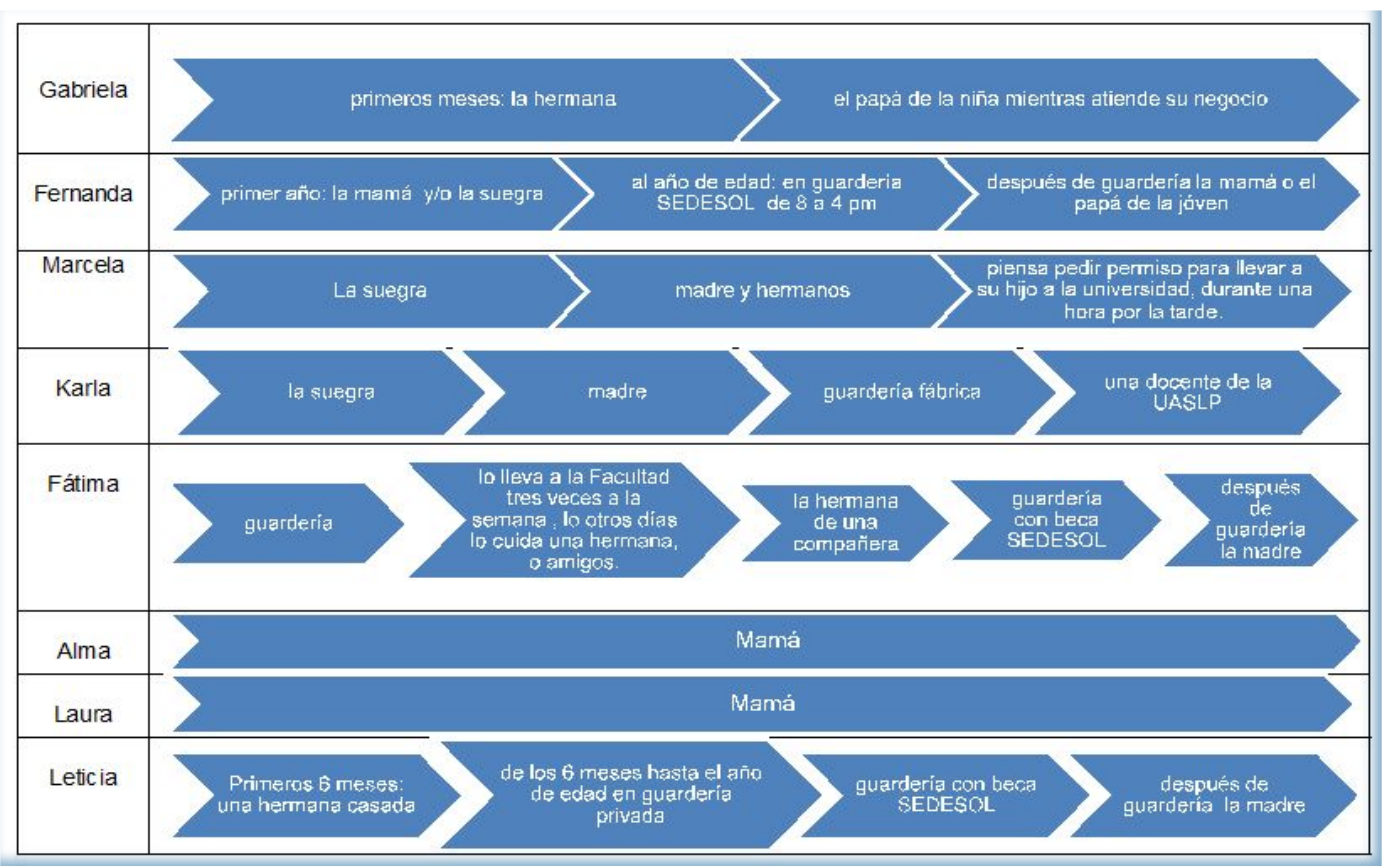

El cuidado de los(as) hijos(as) es un eje a partir del cual se biografía la trayectoria escolar de estas mujeres por la universidad, y se convierte en un elemento a través del cual se define su fragilidad social, pues diversifica las formas en que permanecen en la institución.

Para varias, el cuidado del hijo(a) se 
convierte en un punto de estabilidad, especialmente cuando esta labor la han realizado permanentemente sus madres, pues algunos niños y niñas están al cuidado de sus abuelas por las tardes y en las mañanas asisten a la guardería. Otras abuelas los cuidan durante todo el día, como en los casos de Laura y Alma, sin embargo, para otras jóvenes, el cuidado de los(as) hijos(as) ha llegado a ser un punto de crisis debido a la carencia de una red de apoyo familiar para esta labor. Al respecto, Karla es la única participante que cuenta con la asistencia de una maestra, quien cuida a su hijo dentro de la misma universidad.

... ya tengo como un año de conocerla, de recién que entré aquí, y... pues conoce toda mi situación. Y ella me dijo: -pues mira yo ya terminé [los estudios de maestría] si quieres yo te hecho la mano, y yo te lo cuido-. Me dice: nada más me pasas tu horario, y ya así nos acomodamos-. Pues a ella yo le pago, hasta eso es accesible porque no me cobra mucho, [...] ella casi no viene todos los días aquí [a la universidad], viene jueves, viernes, $y$ a veces lunes y martes, casi los miércoles no, o hay días que me dice que no viene, entonces ella se lo lleva a su casa, pero igual, ella tiene que venir todos los días aquí a checar [...] Tengo que reconocer que me ha echado mucho la mano, porque sí es una gran ayuda, en cuestión de costos y de tiempo, porque pues se acomoda a mi horario, y en costos, en una guardería pagaría más, serían más gastos, y pues a lo mejor no podría cubrirlos, y con ella sí me acomodo, y además que... mi hijo se lleva muy bien con ella, [...][aunque a veces] me complico mucho porque... a veces batallo con los horarios para que me lo cuiden, entonces digo... es que ya me voy a salir (KARLA $\mathrm{P}<4: 34,36: 36$ ).

La situación de Karla es reflejo de las dificultades económicas de la población mexicana, donde es cada vez es más común que los jóvenes que asisten a las universidades públicas lleven a cabo un trabajo de tiempo parcial, si a ello se agrega la situación de madre soltera y huérfana de madre (por lo que no dispone del apoyo de esta figura para el cuidado de su hijo), las condiciones para que permanezca en la universidad son más complejas. En este caso, para que Karla pueda insertarse en ambos escenarios (escolar y laboral) se vuelve fundamental la asistencia que logra obtener para el cuidado de su hijo, lo que a su vez la posiciona en una mayor dependencia debido a lo frágil de los lazos sociales que la apoyan en las funciones de cuidado. La desprotección que vive por parte del Estado y la universidad para acceder a un servicio de guardería acorde a sus posibilidades económicas, como parte de sus derechos como madre y estudiante, la mantiene en la incertidumbre sobre el futuro de los apoyos para el cuidado de su hijo, por tanto, de su porvenir escolar, pues depende en gran medida de la asistencia, la cual gira en torno a los aspectos volitivos y de disposición de las personas con las que establece este lazo social.

El caso de Karla es muy particular debido a que logra conseguir ayuda para el cuidado de su hijo, en otro contexto que es el laboral. Este es un claro ejemplo donde se rompe con la "idealización" de la función compensadora de las familias, al suponer que se convierten en todos los aspectos en la red principal de apoyo para las jóvenes, ante los limitados apoyos del Estado, sin embargo, no todas las familias cuentan con la organización para cubrir aspectos como el cuidado de los(as) hijos(as), incluso con la flexibilidad de cambiar el orden de género que establece a las labores de cuidado como privativas de las mujeres. Frente a la falla de los apoyos en políticas públicas y de la familia para el cuidado de su hijo, Karla logra tener ayuda de su jefa laboral. 
Sí, de hecho me dejan llevar a mi hijo (sonríe). Sí, y ahí me lo llevo, es que salgo de la escuela, y paso y lo recojo, y luego ya me voy al trabajo. Trabajo haciendo el quehacer en un consultorio, soy recepcionista y hago el aseo, y ahí tengo a mi hijo. Pues estoy... son cuatro o cinco horas dependiendo, hasta qué hora haya consulta, hay veces que hay hasta las ocho o las nueve, o hay veces [que] son menos. Pues lo pongo a colorear, o juega con sus carritos, cosas así, como que no es muy inquieto, [...] se supone que es un horario fijo y a veces como salgo más tarde o más temprano, pues, ahí yo llego a la hora que salga, dependiendo de a qué horas pase por mi hijo, ya es a la hora que yo llego (KARLA P<4:246, 198: 198).

La condición de fragilidad social de Karla referente al cuidado de su hijo, nos permite afirmar que el cuidado se convierte en el elemento que en mayor medida puede determinar la permanencia de estas jóvenes en la universidad. En cuanto a la carga de materias, el dinero, el apoyo emocional, las participantes muchas veces logran generar estrategias, pero si sus soportes en el cuidado de sus hijos(as) son inexistentes o precarios, ello determinará su decisión de continuar sus esfuerzos por permanecer en la universidad.

En los antecedes de Karla se encuentra el que renuncia a ocupar el lugar que obtiene para estudiar medicina, debido a que en el momento en que fue admitida se encontraba embarazada y no contaba con el dinero suficiente para sustentar los gastos que la maternidad y la carrera le implicarían. Trabaja un tiempo para poder pagar la universidad, posteriormente ingresa en la Facultad de Ciencias Químicas y estudia el primer semestre, después deserta temporalmente de la universidad para cuidar de su hijo y su madre enfermos, al volver a la universidad vive negligencia institucional, cuya consecuencia la obliga a cursar nuevamente un semestre que ya había aprobado en la Facultad de Ciencias Químicas. Actualmente combina el trabajo y la escuela para mantenerse económicamente ella y su hijo, por tanto, ha generado una serie de estrategias para continuar con sus estudios, sin embargo, si en la vida diaria no cuenta con el apoyo sólido para el cuidado de su hijo, esta joven está expuesta a desertar definitivamente de la institución.

En consecuencia, se debe configurar un cuidado democrático, en el cual es necesario que este acompañado de elementos materiales y recursos para que las tareas de cuidado se desarrollen en circunstancias de igualdad y sean valoradas socialmente, de lo contrario se provoca una injusticia en el cuidado (Sales, 2014). Por lo tanto, es fundamental visibilizar que a la universidad asisten jóvenes que no cuentan con recursos económicos que les permitan integrarse a un sistema de mercantilización para el cuidado de sus hijos(as), así pues, es prioritario atender la dimensión material del cuidado como elemento clave para el ingreso y permanencia de las madres solteras en la universidad.

\section{La red familiar y la legitimación de la maternidad}

Dentro de la estructura familiar se establece una redefinición de la crianza en conjunto, donde en muchos casos las jóvenes madres solteras continúan una relación de noviazgo con el padre de su hijo(a), sin cohabitar ni estar casados. Estos roles parentales y de pareja pueden desarrollarlos de manera provisional, como un medio de ajuste a las condiciones socioeconómicas y para posteriormente transitar a una vida independiente como familia tradicional, o bien, pueden vivirlos de manera permanente $\mathrm{y} / \mathrm{o}$ con algunas modificaciones que presenten durante sus 
vidas. En la red de apoyo principal de las participantes se configuran una variedad de posiciones sobre su maternidad, lo anterior con base en el acceso que las jóvenes presentan sobre el reconocimiento social de esta función. Sofía y el padre de su hija acuerdan continuar viviendo cada uno en casa de sus respectivos progenitores, su hija vive de lunes a viernes con su padre y el fin de semana con Sofía; ella y su pareja adoptaron un patrón de relación de maternidad compartida, de manera que ambos puedan desarrollarse en otros ámbitos de forma más igualitaria.

Como mi pareja [...] su negocio está en la misma casa de sus papás, entonces ahí trabaja y todo, y ahí cuida a la niña, él es el que la cuida, bueno no él al cien por ciento, también yo [...] Ella toda la semana está con su papá y los fines de semana en mi casa, [...] pues ahorita, lo bueno es que su papá está ahí con ella casi de tiempo completo. Entonces, pues prácticamente él es el que la atiende, como quien dice él es la mamá (ríe), más que yo (SOFIA P<1:221, 37: 37).

Si bien, Sofía comparte el rol materno con el padre de su hija, reconoce que actualmente él posee un mayor estatus de madre frente a la niña. En parte reproduce el estereotipo sobre el estatus de madre en función del tiempo que permanece al lado de su hija, por otro lado, establece con su pareja un acuerdo que le permite experimentar una maternidad que marca pautas más óptimas a la organización de su vida diaria como estudiante, lo cual genera mayor flexibilidad sobre el rol materno, al ejercerlo junto con su pareja de manera corresponsable, esto le permite manejar la culpabilidad, elemento recurrente en las madres que ingresan al espacio público y no cumplen totalmente con las funciones sobre el cuidado de sus hijos(as).
En general, estas jóvenes son madres no reconocidas del todo, especialmente en quienes presentan una mayor dependencia de la red familiar se establecen lógicas de género que impiden el que accedan totalmente a la legitimación de su maternidad, pues están insertas en relaciones de desigualdad dentro de su red de cuidados. Valencia y Correa (2006) identifican como un componente de reciprocidad dentro de una red de apoyo, el ejercicio del poder, el cual sobresale cuando un elemento está más necesitado que otro, $\mathrm{y}$ deriva en una desigualdad más marcada entre quienes componen la red. En este sentido, las jóvenes no cuentan con recursos para ser recíprocas en la misma medida o al mismo tiempo en que son beneficiadas, de este modo entran en dinámicas de red que presentan relaciones desiguales de poder, en las cuales los cuidados maternos se convierten en un espacio de intercambio entre ellas y sus propias madres, donde se trasgrede la organización del parentesco, incluso se presentan situaciones de violencia simbólica, así pues, no siempre la negociación es la vía de acceso a los acuerdos que sobre el cuidado se logren, dentro de la red de apoyo.

... es que mi mamá dijo: -Ay no, como tu papá no tuvo un niño, pues ponle Manuel, igual que él-. Pero pues yo no quería, porque dije: ay ¿otro Manuel? Pero pues en sí, como que influyó mi mamá [...] En la comida también, yo le hago una comida [a mi hijo] y nada más está checando, a ver cómo la hiciste, no échale más o... cuando yo le sirvo algo, me dice: -le serviste muy poquito, le serviste mucho, ay por qué le das en ese vaso, mejor dale en el otro, y... por qué le pusiste... mejor cámbialo de ropa..., así como que nada más está ahí diciendo, yo digo una cosa y... no, es lo que ella dice [...] Como todos en mi casa, a lo mejor porque como somos muchos y todos me dicen, Alma, Alma, Alma, 
[mi hijo] ya mejor también agarró, y no, no me dice mamá, a veces sí de repente, de que ay mamá, pero no es muuuy escasa (ALMA $\mathrm{P}<6: 184,413: 413)$.

Alma cede la elección del nombre de su hijo como parte de un acuerdo de red, lo que además ubica a su hijo como extensión de la familia de origen, y no tanto como parte de un grupo familiar establecido junto con su madre y que cohabita con los abuelos. Así mismo, Alma permite que su maternidad sea invisibilizada dentro de su familia nuclear, al no ser nombrada como madre por su hijo, así como al consentir que su madre intervenga constantemente en las decisiones básicas sobre el cuidado del niño.

... desde el principio que yo empezaba a regañarlo o a tener conciencia de: "no hagas eso, eso está mal", mi mamá como que lo defendía mucho, y como que no me daba mi lugar ime entiendes? Siempre era como que yo era la hermana, no como la mamá, y no sigo siendo... ahorita como que siento que no tengo el rol todavía de mamá [...] [Mi familia extensa] yo siento que más le dicen a mi mamá de: "ay Carlos está bien grandote" y no sé qué tanto, pero como hijo de mi mamá... no como mi hijo. $O$ a veces de: "ay se parece a ti" y no sé qué tanto, ese tipo de cosas, sí [me dicen]. Pero más que nada se refieren a mi mamá, como su mamá, ¿me entiendes? No sé [si es] sin querer, o porque... pues obviamente, es obvio que si está viviendo en su casa, y lo está manteniendo a él, pues es como más hijo suyo, pero, en ese tipo de cosas es donde recibo comentarios de mi demás familia [...] Pues... me siento mal, pero pues digo es la verdad, ¿qué puedo hacer yo? [...] Tampoco son cosas que me afecten mucho. O sea digo: - ¿sí, verdad?-. Yo soy la que lo cuido, yo sé en mi interior que yo lo quiero como hijo. Que igual y no estoy todo el tiempo con él, pero que lo baño, que estoy con él, que a veces le doy de comer, que le hago de desayunar, que juego con él. Entonces pues ese tipo de cosas yo también creo que influyen, o tienen algún peso, para sentirme también que soy su mamá (LAURA $\mathrm{P}<8: 146,250$ : 250).

Se observa que la maternidad de las jóvenes madres solteras es parcialmente reconocida en su esfera privada, y una de las razones es la asociación entre el rol materno y el tiempo que se asigna a las funciones de crianza, debido a que ellas invierten gran parte de su tiempo a sus estudios universitarios $y$, en varios casos además a un trabajo, al parecer su maternidad es menos reconocida. Laura apropia sus derechos como madre al acreditarlos en un sentido distinto al ideal de la maternidad tradicional en cuanto al tiempo que debe dedicar a la crianza, esto lo configura en torno a dudas, frente a las cuales plantea que "tiene algún peso", los cuidados que ella da a su hijo, lo cual le permite "sentir" que es su madre; desde su percepción no logra integrar del todo el ser madre, se vive en una idea de incompletud.

La teoría sobre cuidado centra la atención en la jerarquía de género respecto al cuidado, identifica que son las mujeres quienes comúnmente lo realizan, y señala esta situación como una injusticia. Sin embargo, los datos de este estudio indican que esta dominación de género se extiende de manera intergeneracional, entre las propias mujeres, el apoyo que reciben las jóvenes de sus madres para el cuidado de sus hijos(as), a través de las rutinas compartidas entre ellas, permite que las jóvenes estudien, pero a su vez, legitima el que las participantes pierdan poder sobre su maternidad. No obstante, el recibir cuidados debe presentarse en condiciones de calidad $\mathrm{y}$ en un marco de justicia (Flores y Tena, 2014), así, las jóvenes tienen derecho a obtener apoyo en el cuidado, pero salvaguardando su dignidad, por lo tanto, en el cuidado intergeneracional de los(as) 


\section{Cultura de los Cuidados}

hijos(as) de las jóvenes madres solteras no debe naturalizarse la violencia y el descrédito de su maternidad.

En otro orden de ideas, para estas jóvenes estar en la universidad adquiere importancia en el plano material y simbólico, ya que atribuyen que la educación superior les permitirá estar mejor calificadas para ingresar en el mundo laboral, punto en el que consideran se marcará la diversidad en sus biografías maternas.

La red de apoyo familiar para el cuidado de sus hijos(as), les permite no clausurar o posponer su inclusión en la universidad, tampoco trasladan esta aspiración para que la cumplan sus hijos(as) en vez de ellas, pues desean que tanto ellas como sus hijos(as) logren concluir los estudios universitarios. Todas las participantes plantean como objetivo el lograr una vida estable, lo cual asocian con la adquisición de autonomía a partir de adquirir un trabajo que les permita independencia residencial, económica y sobre las decisiones en la crianza de sus hijos(as).

Por otro lado, es más común en las jóvenes que estudian y trabajan, $\mathrm{y}$ las que se encuentran en semestres más avanzados (donde se exige permanecer más tiempo en la universidad), se proyecten hacia el futuro como dotadas de tiempo para convivir con sus hijos(as), indican que en este momento el tener una convivencia limitada con ellos, es un sacrificio que tendrá su recompensa cuando ingresen al mundo laboral: "...yo lo que tengo pensado es terminar mi carrera y dedicarme tiempo a mi hijo ¿no? Ya ganar dinero y poder irme a viajar con él, o no sé, hacer cosas entre él y yo" (ALMA P6:202, 451: 451).

Pues, yo sí sabía que iba hacer pesado y a la vez difícil, en cuestión de tiempos, de las materias, de dedicarle tiempo a mi hijo, porque igual también está chiquito y me necesita, pero pues yo creo que a lo mejor ahorita él no lo resiente tanto, porque esta chico, digo ya si fuera grande y lo dejara, pues yo creo que sí. Entonces, por eso decidí empezar ahorita y no ya más grande, porque a lo mejor se me dificultaría más, también, ya cuando él entre al kínder o cosas así, pues son gastos de él y serían gastos míos, entonces digo, ya por lo menos ahorita aventajo, y ya sé que a lo mejor en un futuro ya podría solventar más los gastos (KARLA P4:248, 78: 78).

... me visualizo pues echándole ganas como una mujer exitosa, entregada a la carrera, y pues en ese lapso también voy a tratar de que me sobren unas dos horas, para poder ir por mi hijo a la guardería, y llevarlo con mi mamá, para verlo en ese lapso, o alcanzar a comer algo con él, para no dejarlo solo todo el día [...] A veces llego en la noche, salgo bien noche de aquí, él está durmiendo, y le digo te amo, aquí estoy, aquí está tu mami, y le digo se va a pasar rápido el tiempo, porque saliendo de [la universidad] ya voy a tener mi horario, vamos a salir, vamos a viajar, y le digo vale la pena el sacrificio papacito, estoy estudiando, y le explico (FATIMA P<69, 109: 109).

Algunas de estas mujeres brindan preponderancia a su educación, siempre y cuando ello no implique limitaciones graves en la educación y manutención de sus hijos(as), plantean "aprovechar" lo que consideran es el "momento preciso", pues el que las y los niños sean pequeños les representa menos costos económicos, lo que les permite otorgar prioridad a su formación profesional.

No cobran conciencia de la inequidad del sistema de género, $\mathrm{y}$ atribuyen a ellas mismas y a la decisión de estar en la universidad, el no poder tener más tiempo para sus hijos(as). Las participantes aspiran a convivir más horas de su rutina diaria con 
sus hijos(as), generan la idea de que al ingresar de lleno al mundo laboral, será más fácil conciliar las labores de crianza con el trabajo; concepción que contrasta con la realidad laboral de muchas mujeres en México. Asocian su futuro profesional con la capacidad de actuar sobre el tiempo de forma más administrada y justa, el combinar el trabajo con lograr suficiente tiempo para los(as) hijos(as), es una aspiración que no problematizan en función de las dinámicas del mundo laboral y la maternidad.

\section{CONCLUSIONES}

La falta de una red de apoyo sólida y predecible para el cuidado de los(as) hijos(as), se convierte en el elemento central que determine el que las jóvenes puedan continuar con sus estudios universitarios, de modo que, se confirma al cuidado como una necesidad elemental a cubrir para la integración de las mujeres en el mundo público, en este caso, en las carreras de ciencias exactas y tecnología de la Facultad de Ciencias Químicas, de la UASLP, México.

De acuerdo con Guadalupe Ordaz (2010), en México a partir de 1980, se presentan cambios en las reformas estructurales, lo que significa un menor papel por parte del Estado en la provisión de seguridad social. Aunado al ajuste que ha traído las políticas económicas, todo ello derivó en que las familias presenten una "sobrecarga de responsabilidades", que afectan en mayor grado a las mujeres, quienes dentro de sus familias comúnmente viven condiciones de desigualdad de género. En este sentido, Sales (2014) plantea que se debe configurar un cuidado democrático, donde prevalezca entre el dependiente y el cuidador la negociación sobre las condiciones de cuidar, sin embargo, dicha democracia no depende solamente de marcos de interacción, también es necesario que esté acompañada de elementos materiales y recursos para que las tareas de cuidado sean en circunstancias de igualdad y valoradas socialmente, de lo contrario se provoca una injusticia en el cuidado.

Las jóvenes madres solteras universitarias experimentan injusticias en el cuidado especialmente cuando no logran cubrir su dimensión económica, elemento clave para la deserción y el rezago escolar de estas jóvenes. Dicha dimensión rige el que ellas permanezcan en la universidad, pues sostienen que uno de los motivos por los que invierten en su educación es el que sus niños(as) son pequeños(as) y generan menos gastos monetarios, de lo contrario, tendrán como prioridad la educación y manutención de sus hijos(as) sobre su asistencia a la universidad.

Evidenciamos que en la mayoría de los casos las trayectorias en el cuidado de los(as) hijos(as) no son lineales, salvo en las estudiantes que fueron madres adolescentes $\mathrm{y}$ a quienes sus padres exigieron que rompieran toda relación con el padre de sus hijos(as), así, la familia de origen asume la responsabilidad total de ellas y sus hijos(as). Por otro lado, la red de apoyo intergeneracional no siempre está presente, madre-abuelas, lo que da lugar a la diversidad de figuras de cuidado, aunque en todos los casos son principalmente mujeres.

Algunas de estas jóvenes experimentan situaciones de violencia dentro de su red de apoyo, el compartir la relación de cuidado de sus hijos(as) junto con sus madres $y$, a su vez, la permanencia del cuidado de la madre hacia la joven, mantiene a las participantes en una relación diferencial de poder, ante la cual, adicionalmente se entrecruza la falta de conocimiento y ejercicio de sus derechos sexuales y reproductivos, a través de los cuales podrían exigir el respeto básico que 
merecen como madres -por tanto, de sus derechos humanos- a pesar de vivir en una situación de dependencia residencial y económica; hecho que no les permite acceder a un amplio bienestar sobre su maternidad.

Para que las prácticas del cuidado se desarrollen en un marco de justicia se requiere profundizar en el estudio de las jóvenes universitarias que son madres, $y$ generar políticas del cuidado para que la maternidad no les limite ejercer su derecho a la educación superior, del mismo modo, el establecer redes de apoyo por parte del Estado, la Universidad y la comunidad en general, les permitirá desarrollar las tareas de cuidado en circunstancias de igualdad.

\section{REFERENCIAS}

- Aguirre, R. (2005). Los cuidados familiares como problema público y objeto de políticas. En I. Arriagada (Ed.), Políticas hacia las familias, protección e inclusión sociales. (pp.4-11). Chile: CEPAL. Recuperado de https://dds.cepal.org/eventos/presentaciones/2005/06 28/Rosario Aguirre.pdf.

- Alonso-Sanz, A.; Iglesias, M.J. \& Lozano, I. (2015). La conciliación estudiantil -familiar y el proceso de enseñanza- aprendizaje en Educación Superior: un estudio cualitativo. Educatio Siglo XXI, 33(3), 223-246. Recuperado de http://rua.ua.es/dspace/handle/10045/51609.

- Batthyány, K. (2000). Maternidad y trabajo asalariado: Las estrategias de cuidado infantil de las mujeres en Motevideo, estudio de caso múltiple. Recuperado de http://cienciassociales.edu.uy/departamentodesociol ogia/wp-

content/uploads/sites/3/2013/archivos/11\%20Batthya ny.pdf.

- Batthyany, K. El tema de cuidados es el nudo crítico de la desigualdad de género. CLACSO Tv. Argentina. Recuperado de https://www.youtube.com/watch?v=2jrp03JgTMo.

- Cerri, C. \& Alamillo-Martínez, L. (2012). La organización de los ciudadanos, más allá de la dicotomía entre esfera pública y esfera privada.
Gaceta de Antropología, 28 (2), Recuperado de http://www.gazeta-antropologia.es/?p=4145.

- Collin, F. (1992). Borderline. Por una ética de los límites. ISEGORIAA, 6, 83-95. Recuperado de http://isegoria.revistas.csic.es/index.php/isegoria/arti cle/view/325/326.

- Esteban, M. L. (2017). Los cuidados, un concepto central en la teoría feminista: aportaciones, riesgos y diálogos con la antropología. QuAderns-e, 22 (2), 33$48 . \quad$ Recuperado de https://www.antropologia.cat/files/3 Esteban.pdf.

- Esteban, M.L. \& Otxoa, I. (2010). El debate feminista en torno al concepto de cuidados. Cip-Ecosocial. 10, 110. Recuperado de https://docplayer.es/8844343-Eldebate-feminista-en-torno-al-concepto-de-

cuidados.html.

- Ezquerra, S. (2011). Crisis de los cuidados y crisis sistémica: la reproducción como pilar de la economía llamada real. Investigaciones Feministas, 2, 175-194. Recuperado de http://revistas.ucm.es/index.php/INFE/article/view/3 8610/37335. Acceso el 09/08/2018.

- Flores, R. L \& Tena, O. (2014). Maternalismo y discursos feministas latinoamericanos sobre el trabajo de ciudadanos: un tejido en tensión. Revista de Ciencias Sociales, 50, 27-42. Recuperado de http://revistas.flacsoandes.edu.ec/iconos/article/view $\angle 1426$.

- Gómez, G. M. \& Agudelo, M. E. (2017). Redes familiares y vecinales en el cuidado de niños y niñas. Infancias imágenes, 16 (1), 60-71. Recuperado de http://revistas.udistrital.edu.co/ojs/index.php/infanci as/article/viewFile/11457/12947.

- Hérnandez, A. L. (2016). Cuidar se escribe en femenino: redes del cuidado familiar en hogares de madres migrantes. Psicoperspectivas Individuo $y$ sociedad, 15 (3), 46-55. Recuperado de https://www.psicoperspectivas.cl/index.php/psicope rspectivas/article/view/784.

- López-Ibor, R. A.; Escot, L. \& Fernández, J. A. (2010). La predisposición de las estudiantes universitarias a autolimitarse profesionalmente en el futuro por razones de reconciliación. Estudios de Economía Aplicada, 28-1, 1-32. Recuperado de http://www.redalyc.org/articulo.oa?id=30120313013.

- Martín Palomo, M. T. (2008). Los cuidados y las mujeres en las familias. Política y Sociedad, 45 (2), 2947. Recuperado de http://revistas.ucm.es/index.php/POSO/article/view/ POSO0808230029A.

- Martín Palomo, M. T. (2008). Domesticar el trabajo: Una reflexión a partir de los cuidados. Cuadernos de relaciones laborales, 26 (2), 13-44. Recuperado de http://revistas.ucm.es/index.php/CRLA/article/view/ CRLA0808220013A. 


\section{Cultura de los Cuidados}

- Medialdea, B. (2016). Discriminación laboral y trabajo de cuidados: El derecho de las mujeres jóvenes a no elegir. ATLÁNTICAS. Revista internacional de estudios feministas, 1 (1), 90-107. Recuperado de http://revistas.udc.es/index.php/ATL/article/view/ari ef.2016.1.1.1792.

- Ordaz, G. (2010). Políticas públicas y familias en México. Tendencias y desafíos. En S. Lerner \& L. Melgar (coords.), Familias en el siglo XXI: Realidades diversas y políticas públicas (pp. 343-358). México: El Colegio de México.

- Pacheco, L. C. (2018). Académicas universitarias: el tiempo entre los libros y el cuidado. Revista de Investigación sobre los Estudios de Género, 22, 9-30. Recuperado de http://revistasacademicas.ucol.mx/index.php/genero s/article/view/1322.

- Programa de las Naciones Unidas para el Desarrollo. 5 Igualdad de Género. Recuperado de http://www.undp.org/content/undp/es/home/sustai nable-development-goals/goal-5-genderequality.html.

- Roldán, E. L; Ayala, M. C; Pérez, D. P \& Romero, N. Y. (2016). Redes sociales de apoyo a la crianza de los menores en etapa escolar primaria. Revista Científica General José María Córdoba, 14 (18), 73-95. Recuperado de

https://www.revistaesmicgimc.com/index.php/esmic larticle/view/43.
- Sales, T. (2014). Ciudadanía y cuidados; apuntes para política feminista democrática. Daimon. Revista Internacional de Filosofia, (63), 159-174. Recuperado de http://revistas.um.es/daimon/article/view/189751.

- Sales, T. (2015). Cuidados poder y ciudadanía. Las Torres de Lucca: revista internacional de filosofía política, (6), 7-45. Recuperado de https://dialnet.unirioja.es/servlet/articulo?codigo $=51$ $\underline{72676}$

- Sales, T. (2016). Contra la precariedad, con la precariedad; cuidados y feminismo. Oxímora Revista Internacional de Ética y Política, (8), 53-62. Recuperado de

http://revistes.ub.edu/index.php/oximora/article/vie w/15393.

- UASLP. Universidad Autónoma de San Luis Potosí. Resumen ejecutivo del informe de rectoría 2011-2012. Indicadores institucionales. (2012). Recuperado de http://www.uaslp.mx/Documents/Universidad/Sitio \%20rector/Informes/20112012/indicadores\%20institucionales.pdf.

- Valencia, F. \& Correa, A. (2006). Ayuda mutua e intercambio: Hacia una aproximación conceptual. Revista Científica Guillermo de Ockham, 4 (2), 71-82, Recuperado de http://www.redalyc.org/articulo.oa?id=105316853006. 